\title{
Biography of Professor Rienk Brouwer
}

\section{O. M. van Andel ${ }^{1}$ and A. C. de Roon ${ }^{2}$}

${ }^{1}$ Department of General Botany, State University of Utrecht, Lange Nieuwstraat 106, 3512 PN Utrecht, Netherlands

2 Department of Plant Taxonomy, State University of Utrecht, Heidelberglaan 2, 3584 CS Utrecht, Netherlands

Rienk Brouwer was born in Oudehaske, Friesland, Netherlands, in 1918. He finished Grammar School in 1938 and was called into military service. In the 'May War' of 1940 he fought at the Grebbeberg and was taken prisoner of war. After being released he started to study biology at the State University of Groningen in the autumn of 1940. When the universities had to close in 1943 he was forced into hiding until the summer of 1945, when he resumed his studies. In 1946 he was called into military service again and was posted to the former Dutch East Indies, where he stayed until 1950 with an interruption of a few months in Europe, during which time he was married. In his capacity of army officer one of his major talents, also very important in his later career, became apparent, namely his great interest in young people and his ability to be on good terms with them and handle them even in difficult situations.

After his return to the Netherlands Brouwer resumed his studies in Groningen. In 1952 he took his M. Sc. with plant physiology as major subject and started to work on a thesis under the supervision of the plant physiologist Professor Dr W. H. Arisz. For many years the subject of the research of Arisz and his students had been the processes of uptake and translocation in plant tissue. In the years after World War II the interest was directed for the greater part towards the uptake process of ions in intact plants, partly under the influence of the ideas on active uptake by roots as developed by investigators as D. R. Hoagland (USA) and H. Lundegårdh (Sweden). The subject of Brouwer's thesis: the processes controlling the uptake of water and ions by roots and their interrelation, has always retained his interest as well as the idea that those processes, in addition to the study in plant parts, should be studied in the whole plant.

After obtaining his Ph. D. in 1954 Brouwer continued to do research in Groningen, extending it, among other things, to the study of relations between function and structure in plants. There was a mutual respect between Arisz and Brouwer, which led to stimulating discussions and made their relationship last after Brouwer had left Groningen. Teaching was part of his task, but, considering the small number of biology students in those times, this was not a very demanding duty and it left him free to perform it in a personal way.

In 1957 Brouwer was appointed associate professor at the Botanical Laboratory of the Agricultural University at Wageningen. In 1958 he became Senior Plant 
Physiologist at the Plant Growing Deparment of the Insitute of Biological and Chemical Research on Field Crops and Herbage, the IBS, at Wageningen. This meant that he could resume the research on root physiology with adequate technical assistance and ample facilities. His old interest for agriculture facilitated the integration of his own research with the type of agricultural problems that prevailed at the IBS. A period of extensive scientific productivity followed; he published ca. 35 publications, alone or in co-operation with colleagues at the IBS or other institutes in Wageningen.

In particular the phenomenon of the co-ordinated growth of shoot and roots developing simultaneously in mutual dependence and in mutual competition, roused his interest. This led to extensive research on the interrelation between the growth of various organs. The agricultural-ecological approach of research workers as $\mathrm{Dr}$ W. H. van Dobben and the interest in developing simulation models of Dr C. T. de Wit contributed greatly to the progress of the research and stimulated the development of the concept 'functional equilibrium'. Guests from abroad spent some time at the IBS to mutual benefit, whereas Brouwer was invited to give a series of lectures during a stay of several months at Cornell University, Ithaca, N.Y. (USA). Teaching was not part of his assignment during this time but his interest in it found an outlet in a teachership at the STOVA (College for Laboratory Technicians) in Wageningen and a chairmanship of the board of the Grammar School in Ede.

In 1969 Brouwer was appointed associate professor at the Department of Plant Physiological Research of the Agricultural University in Wageningen. His appointment as Professor in General Botany at the State University in Utrecht, as successor of Professor Dr R. van der Veen, followed in 1971. The title of his inaugural address: 'Analysis and synthesis in plant physiology', reflected his views on the way plant physiology should be approached and taught.

Van der Veen, having spent a long time in the former Dutch East Indies, was very keen on the importance of applied plant physiology in agriculture and industry and he gave this aspect considerable attention in his teaching. Brouwer was expected to continue along the same lines, which he did to a certain extent, but soon he took his own way. The enormous expansion of the Dutch Universities in the fifties and sixties was slowing down in the early seventies and it became clear that it would end in a stand-still. There was little opportunity to attract young botanists which could have led to the development of a 'school of research'. Nevertheless Brouwer has had a great influence on education and research in botany in Utrecht. Using the causal-analytic method he would always aim at a synthesis directed at the whole plant or an ecosystem. The section 'Whole Plant Physiology' of the Department of General Botany, set up after his appointment, soon began to draw such numbers of students that there was sometimes hardly room for them. This problem was solved by finding a place for them in institutes in Wageningen or elsewhere, which also provided the students with an opportunity to participate in applied research. Brouwer's appeal on students was possibly in the first place his enthousiasm for botanical research and his amiable personality, but certainly also his ability to bridge the so-called gap, whether existing or not, between basic and applied research. 
When one Ph. D. student started a study of the ash coppice and another became interested in the ecophysiology of the sand sedge, part of the research was moved out of the laboratory into the field, and gradually Brouwer's interest shifted more and more to ecophysiology. His group started a joint teaching program with the Department of Botanical Ecology and research projects were set up in which members of both groups participated. Brouwer had a stimulating influence in these developments, as well as in the organization of a national grassland study group with participants from the Institute of Ecology of the Royal Netherlands Academy of Arts and Sciences and from the Universities of Groningen and Utrecht, now supported by BION (The Netherlands Foundation for Biological Research).

From the above it is clear that Brouwer was not interested in taking an isolated position but, on the contrary, he was convinced of the importance of co-operation and openness. It was this attitude that also played an important part in his administrative activities, whether it was within the Subfaculty of Biology in Utrecht or in the various committees or boards of managements outside it of which he was a member.

Many of the colleagues who have been in touch with Brouwer will have profited by it, and they will remember him as somebody who is always ready to help. Without doubt these contacts have also been important to Brouwer himself. The most important thing in his career, however, may have been the fact that he has contributed an essential part to the education, both scientific and personal, of many students. That this has been appreciated is without doubt.

Brouwer's social interest was not only evident in his work but also in his private life. The Church and the political party, of which he is a member, never called on him in vain. He has officiated in various functions in the Dutch Reformed Church and was a member of the town council of Wageningen. His scientific merits have been recognized, among other things, by his appointment as a member of the Royal Netherlands Academy of Arts and Sciences.

His fairness, patience and enthusiasm, will be remembered with pleasure and appreciation by those who had the privilege to meet him or to work with him. These qualities will continue to stimulate the people around him in the coming years. 